\title{
Penggunaan metode collection-centered dalam kegiatan evaluasi koleksi di Perpustakaan Institut Agama Islam Negeri (IAIN) Syekh Nurjati Cirebon
}

\author{
Yunus Winoto ${ }^{1}$ dan Dewi Kusumawati ${ }^{2}$ \\ ${ }^{1,2}$ Universitas Padjadjaran, J1. Raya Jatinangor Sumedang KM 21 Bandung \\ e-mail :yunuswinoto@gmail.com
}

\begin{abstract}
This research aims to increase selector knowledge about collection and use of collection-centered method so that it can measure success in developing and managing collections effectively. The location of the study was conducted at the IAIN Syekh Nurjati Library Center in Cirebon. The method used is a qualitative research method with a case study approach. Data obtained through observation, in-depth and unstructured interviews supported by triangulation by college librarians. Based on the results of the study it can be concluded that the results of the evaluation of the list checking process carried out by the IAIN Syekh Nurjati Cirebon Library Center has been well marked by the process of mapping the strength of collections, using the checklist form, overcoming the existing collection gap to determine collection priorities based on checking by librarians. The collection of IAIN Syekh Nurjati Cirebon Library Center has fulfilled three indicators of collection standards and continues to make efforts to perfect the collection in accordance with applicable standards. Therefore, with the evaluation of the collections achieved by the Syeh Nurjadi IAIN library center, it is expected that the available collections can fulfill the quantity and quality elements while paying attention to the demands, needs and tastes of the library user community, in this case academic community of IAIN Syeh Nurjati Cirebon.
\end{abstract}

Keywords: collection evaluation; collection standard; collection development; University library.

\begin{abstract}
ABSTRAK
Penelitian ini bertujuan untuk meningkatkan pengetahuan selektor tentang pengumpulan dan penggunaan metode collection-centered dalam mengukur keberhasilan mengembangkan dan mengelola koleksi secara efektif. Penelitian dilakukan di Pusat Perpustakaan IAIN Syekh Nurjati Cirebon. Metode yang digunakan adalah metode penelitian kualitatif dengan pendekatan studi kasus. Data diperoleh melalui observasi, wawancara mendalam dan tidak terstruktur dengan didukung triangulasi oleh pustakawan perguruan tinggi. Berdasarkan hasil penelitian dapat disimpulkan bahwa hasil evaluasi terhadap proses list checking yang dilakukan Pusat Perpustakaan IAIN Syekh Nurjati Cirebon sudah baik dengan ditandai proses pemetaan kekuatan koleksi, analisis kebutuhan menggunakan form checklist, mengatasi kesenjangan koleksi yang ada hingga menentukan prioritas koleksi berdasarkan pengecekan oleh pustakawan. Koleksi di Pusat Perpustakaan IAIN Syekh Nurjati Cirebon telah memenuhi tiga indikator standar koleksi dan terus melakukan upaya untuk menyempurnakan koleksi sesuai dengan standar yang berlaku. Oleh karena itu dengan hasil evaluasi koleksi yang dicapai pusat perpustakaan IAIN Syeh Nurjadi Cirebon diharapkan koleksi yang tersedia dapat memenuhi unsur kuantitas mapun kualitas dengan tetap memperhatikan tuntutan (demand), kebutuhan (needs) maupun selera (taste) dari masyarakat pengguna perpustakaan, dalam hal ini sivitas akademika IAIN Syeh Nurjati Cirebon.
\end{abstract}

Kata Kunci : evaluasi koleksi; standar koleksi; pengembangan koleksi; perpustakaan perguruan tinggi. 


\section{A. PENDAHULUAN}

Perguruan tinggi merupakan suatu lembaga ilmiah dimana segala proses yang terlibat didalamnya meliputi kehidupan proses belajar mengajar dan proses peningkatan kecerdasan berlandaskan akhlak yang tinggi. Di dalam sebuah perguruan tinggi tentu terdapat sinergi antarsemua elemen civitas akademika meliputi dosen, mahasiswa dan staff guna menunjang terlaksananya tujuan perguruan tinggi yaitu tri dharma perguruan tinggi.

Dalam jurnal "Menciptakan Hubungan Harmonis di Perguruan Tinggi", menurut (Muda 2014) dosen adalah tenaga pendidik yang mengabdi pada perguruan tinggi. Dalam menjalankan tugasnya, dosen menghadapi peserta didiknya yang disebut mahasiswa. Dosen sangat berperan dalam upaya meningkatkan potensi peserta didik, antara lain kreativitas, inovatif, antisipatif, tanggung jawab dan kepribadian. Mahasiswa adalah komponen perguruan tinggi yang memiliki jumlah sangat besar dalam lingkungan kampus. Mahasiswa juga merupakan peserta didik yang menuntut ilmu dan memperoleh ilmu serta menjalankan kegiatan lainnya di lingkungan internal maupun eksternal kampus. Sedangkan staff dalam perguruan tinggi adalah mereka yang memiliki kewajiban, tanggung jawab serta wewenang dalam melaksanakan kebijakan dan tujuan dari perguruan tinggi tersebut. Salah satu staff yang memiliki peranan penting dalam mendukung terlaksananya program tri dharma perguruan tinggi adalah seorang pustakawan.

Menurut UU No. 43 tahun 2007 menyatakan bahwa pustakawan adalah seseorang yang memiliki kompetensi yang diperoleh melalui pendidikan dan atau pelatihan kepustakawanan serta mempunyai tugas dan tanggung jawab untuk melaksanakan pengelolaan dan pelayanan kepustakaan. Pustakawan tidak hanya berorientasi pada pelayanan sirkulasi, tapi dituntut untuk dapat memberikan informasi secara cepat, tepat, akurat dan efisien dari segi waktu dan biaya. Hal ini diperkuat dengan pendapat dari (Sulistyo-Basuki 1991) yang menyatakan bahwa "pustakawan adalah tenaga profesional yang dalam kehidupan sehari-hari berkecimpung dengan dunia buku. Dengan situasi demikian sudahlah layak bila pustakawan menganjurkan masyarakat untuk giat membaca. Pustakawan pun dituntut untuk giat membaca demi kepentingan profesi, ilmu, maupun pengembangan kepribadian si pustakawan itu sendiri”(Sulistyo-Basuki 1991)

Dukungan perpustakaan perguruan tinggi dapat berupa penyediaan koleksi yang sesuai dengan kebutuhan mahasiswa (pemustaka) sehingga menjadikan perpustakaan sebagai bagian integral dalam kegiatan belajar mahasiswa. Karena pada hakikatnya, perpustakaan adalah unit kerja yang mengelola sejumlah bahan pustaka dan dapat dimanfaatkan oleh pengguna sesuai dengan fungsinya yaitu sebagai sumber informasi.

Perpustakaan perguruan tinggi merupakan salah satu jenis perpustakaan yang paling banyak memberikan kontribusi dalam hal penyebaran informasi ilmiah di bidang pendidikan. Perpustakaan Perguruan tinggi bersama-sama dengan unit lain, turut melaksanakan tri dharma perguruan tinggi dengan cara memilih, menghimpun, mengolah, merawat, serta melayankan sumber informasi kepada lembaga induknya pada khususnya dan civitas akademika pada umumnya. Menurut Sulistyo-Basuki perpustakaan perguruan tinggi adalah :

Perpustakaan yang terdapat pada perguruan tinggi, badan bawahannya, maupun lembaga yang berafiliasi dengan perguruan tinggi dengan tujuan utama membantu perguruan tinggi dalam mencapai tujuannya. Tujuan perguruan tinggi di Indonesia dikenal dengan istilah "Tri Dharma Perguruan Tinggi” yaitu pendidikan, penelitian dan pengabdian kepada masyarakat. Oleh karena itu, perpustakaan perguruan tinggi berupaya untuk membantu jalannya ketiga dharma perguruan tinggi tersebut (Sulistyo-Basuki 1991). 
Dalam perpustakaan perguruan tinggi terdapat hubungan segi tiga antara pustakawan, mahasiswa, dan pengajar. Hubungan segi tiga ini menunjukkan bahwa pengajar dan mahasiswa berhubungan langsung dengan pustakawan dalam mencari dan menelusur suatu informasi. Maka dari itu, pustakawan yang dimiliki oleh perguruan tinggi haruslah memiliki kemampuan dalam sebuah subjek dengan berlandasakan telah mengikuti pendidikan kepustakawanan yang sesuai dengan standar profesi pustakawan. Dengan berbekal pendidikan tersebut, diharapakan pustakawan akan membawa implikasi agar mahasiswa dapat menggunakan bahan pustaka yang ada di perpustakaan guna kepentingan mahasiswa dalam menunjang pembelajaran. Oleh karena itu, tersedianya koleksi menjadi suatu hal yang sangat penting bagi perpustakaan perguruan tinggi dalam memberikan layanan bagi pemustaka (Sulistyo-Basuki 1991).

Berbicara lebih jauh tentang perpustakaan perguruan tinggi terdapat beberapa beberapa hasil penelitian yang terkait dengan topik yang menjadi bahasan dalam tulisan ini serta sebagai pijakan dalam penelitian yang mengkaji tentang evaluasi koleksi ini. Berkaitan dengan hal ini ada beberapa penelitian sebelumnya yang pernah dilakukan terkait dengan pengembangan koleksi yaitu : 1). penelitian yang berjudul "Pengembangan koleksi pada perpustakaan perguruan tingi swasta di wiayah Priangan Timur". Oleh Yunus Winoto, dkk (2012);, 2). Penelitian yang berjudul "Studi tentang kerjasama antar perpustakaan perguruan tingggi swasta di kopertis wilayah IV Jawa Barat". Oleh Tati Sumiati, Yunus Winoto dan Sukaesih (2013); 3). Penelitian yang berjudul, "Strategi pengembangan koleksi pada beberapa perguruan tinggi Islam Negeri di Jawa Barat Dan Provinsi Banten". Oleh Rohanda dan Tine Silvana (2015) serta 4). penelitian yang berjudul "Model kerjasama antar perpustakaan perguruan tinggi Islam di Jawa Barat", oleh Yunus Winoto, dkk (2017). Adapun dari beberapa hasil penelitian tersebut menggambarkan bahwa pengembangan koleksi merupakan salah satu faktor yang menentukan keberhasilan penyelenggaraan perpustakaan. Melalui pengembangan koleksi yang baik akan menghasilkan koleksi yang kuat, berkualitas sesuai dengan tuntutan, kebutuhan dan selera dari masyarakat penggunanya. Salah satu tahapan dalam pengembangan koleksi adalah melakukan evaluasi koleksi.

Koleksi merupakan hal yang sentral dalam sebuah perpustakaan sebab koleksi ialah sesuatu yang akan dilayankan kepada pemustaka. Koleksi yang terdapat di perguruan tinggi tidak akan jauh berbeda dengan koleksi yang terdapat di perpustakaan pada umumnya. Koleksi perpustakaan terdiri dari koleksi bahan buku seperti buku, majalah, koran, jurnal, dan sebagainya. Sedangkan koleksi bahan non-buku terdiri dari $e$-journal, $e$ book, video, film, dan sebagainya. Besarnya koleksi perpustakaan ditentukan oleh berbagai faktor seperti jumlah program studi, jumlah mata kuliah (dasar umum, dasar keahlian, bidang studi), tingkat pendidikan (akademik, politeknik, institut, universitas), kegiatan penelitian, banyaknya buku ajar per mata kuliah, dan lain-lain.

Agar koleksi perpustakaan tetap tersedia dan mutakhir, maka koleksi perpustakaan perlu dikembangkan secara terus menerus. Untuk mengembangkan koleksi yang ada di perpustakaan, biasanya perpustakaan memiliki pedoman tertulis mengenai pengembangan koleksi perpustakaan yang biasanya disebut dengan kebijakan pengembangan koleksi. Begitu pula dengan ketersediaan koleksi yang ada di perpustakaa harus ditinjau apakah koleksi perpustakaan telah memenuhi kebutuhan informasi bagi pemustaka atau tidak. Maka dari itu, kegiatan evaluasi koleksi harus selalu dilakukan oleh setiap perpustakaan.

Evaluasi koleksi ialah upaya menilai daya guna dan hasil guna koleksi dalam memenuhi kebutuhan civitas akademik serta program perguruan tinggi. Menururt Wallace \& Fleet dalam buku Library Evaluation : A Casebook and Can-Do Guide evaluasi koleksi merupakan "Kegiatan penilaian yang berfokus pada penentuan kekuatan dan kelemahan 
dari sebuah koleksi perpustakaan, bagaimana koleksi tersebut dapat mendukung dan memajukan misi dan tujuan perpustakaan yang menaunginya, dan nilai dari koleksi tersebut bagi pengguna perpustakaan (Wallace dan Fleet 2001).

ALA's Guide to the Evaluation of Library Collections membagi dua metode dalam evaluasi koleksi yaitu berdasarkan collection-centered dan use-centered. Dalam masingmasing kategori terdapat sejumlah metode evaluatif yang spesifik. Metode ini berfokus pada koleksi yang bersifat cetak, namun seringkali ada beberapa elemen yang juga dapat digunakan dalam evaluasi koleksi yang bersifat elektronik.

Metode berdasarkan collection-centered mempunyai empat kategori dalam melakukan evaluasi koleksi yaitu sebagai berikut: (1) melalui pencocokan daftar tertentu, bibliografi, atau katalog; (2) penilaian dari pakar; (3) perbandingan data statistik; (4) perbandingan pada berbagai standar koleksi. Dengan demikian, evaluasi koleksi perpustakaan menjadi hal yang sangat perlu dilakukan secara berkesinambungan guna membantu pustakawan secara komprehensif dalam memahami koleksi dan mengetahui seberapa besar kebutuhan pemustaka terhadap informasi.

Kemudian jika dilihat dari tujuannya, menurut Pedoman Perpustakaan perguruan Tinggi ada beberapa tujuan dari evaluasi koleksi yakni sebagai berikut:

1) Mengetahui mutu, lingkup, dan kedalaman koleksi.

2) Menyesuaikan koleksi dengan tujuan dan program perpustakaan serta lembaga induknya.

3) Mengikuti perubahan, perkembangan, sosial budaya, ilmu dan teknologi.

4) Meningkatkan nilai informasi

5) Mengetahui kekuatan dan kelemahan koleksi

6) Menyesuaikan kebijakan penyiangan koleksi (Direktorat Jenderal Pendidikan Tinggi 1994)

Pusat Perpustakaan IAIN Syekh Nurjati Cirebon merupakan perpustakaan yang terdapat di lingkungan IAIN Syekh Nurjati Cirebon. Dalam melaksanakan tugas sehariharinya yaitu melayani pemustaka yang terdiri dari para mahasiswa program S1, program pascasarjana, para dosen, karyawan, alumni serta tamu dari luar lingkup IAIN Syekh Nurjati Cirebon. Kehadiran Pusat Perpustakaan IAIN Syekh Nurjati Cirebon sangat dibutuhkan dalam hal pengadaan bahan bacaan dan memenuhi kebutuhan informasi pemustaka.

Pusat Perpustakaan IAIN Syekh Nurjati Cirebon per 31 Desember 2017 memiliki jumlah koleksi sebanyak 30.801 judul dan 65.189 eksemplar dengan rincian jenis pustaka yaitu buku teks/ umum, referensi, tandon, the Asia Foundation, skripsi, thesis, laporan penelitian, jurnal ilmiah, majalah, surat kabar, digital, prosiding, klipping, laporan tahunan, indeks/ katalog, dan Cirebonese Corner ${ }^{1}$. Hal tersebut sejalan dengan Undang-Undang Republik Indonesia No.43 tahun 2007 yang berbuyi "koleksi perpustakaan adalah semua informasi dalam bentuk karya tulis, karya rekam dalam berbagai media yang mempunyai nilai pendidikan yang dihimpun, diolah, dan dilayankan".

Koleksi yang terdapat di Pusat Perpustakaan IAIN Syekh Nurjati Cirebon ini diperoleh dari anggaran DIPA, hibah dari Bank Indonesia, hibah Perpustakaan Nasional Republik Indonesia, hibah alumni, hibah mahasiswa, dan hibah dari Departemen Agama Republik Indonesia. Koleksi buku yang berasal dari anggaran DIPA yaitu koleksi dengan kategori Islam dan umum yang pada umumnya digunakan dalam proses belajar seluruh mahasiswa IAIN Syekh Nurjati Cirebon.

\footnotetext{
${ }^{1}$ Hasil wawancara dengan Ibu Tuti Alawiyah selaku koordinator bidang pengembangan dan pengadaan bahan pustaka Pusat Perpustakaan IAIN Syekh Nurjati Cirebon, 1 Februari 2018.
} 
Dalam kegiatan pelayanannya, pada Desember 2017 perpustakaan ini melayani sekitar 388 orang per hari yang datang ke bagian layanan umum dan 35 orang per hari ke layanan Bank Indonesia (BI) Corner ${ }^{2}$. Dengan banyaknya pemustaka dan beragamnya kebutuhan pemustaka, pihak pusat perpustakaan dituntut untuk mampu menyediakan berbagai koleksi yang dapat memenuhi kebutuhan pemustaka.

Evaluasi koleksi menjadi hal penting untuk dilakukan secara berkesinambungan guna membantu pustakawan dalam mengetahui secara komprehensif tentang koleksi yang dimiliki dan seberapa besar kebutuhan pemustaka yang dapat terpenuhi, belum dilakukan oleh pihak Pusat Perpustakaan IAIN Sykeh Nurjati Cirebon. Hal ini dikarenakan sebagian besar staff yang bertugas tergolong masih muda dalam menangani perpustakaan dan hanya dua orang memiliki latar belakang perpustakaan ${ }^{3}$. Hal ini tentunya berdampak pada pemustaka dalam memenuhi kebutuhan informasinya. Pemustaka mengaku sering menemui kesulitan dalam menemukan beberapa kebutuhan terhadap sumber bacaan dan pada akhirnya sering kali tidak terpenuhi ${ }^{4}$.

Berdasarkan fenomena diatas untuk mengetahui apakah koleksi pada Pusat Perpustakaan IAIN Syekh Nurjati Cirebon sudah sesuai dengan harapan yaitu dapat memenuhi kebutuhan pemustaka, maka penulis tertarik untuk meneliti mengenai evaluasi koleksi berdasarkan metode collection-centered di Pusat Perpustakaan IAIN Syekh Nurjati Cirebon.

\section{B. TINJAUAN PUSTAKA}

Koleksi merupakan sebuah modal bagi perpustakaan atau sejumlah kekayaan yang dimiliki oleh perpustakaan dalam memberikan layanan informasi kepada pemustaka untuk dapat digunakan sebagai sarana belajar di perpustakaan. Oleh karena itu, informasi yang diberikan kepada pengguna adalah berasal dari koleksi yang disediakan yang disesuaikan dengan kebutuhan pemustaka.

Berbicara mengenai koleksi perpustakaan, Johnson menyatakan "Collection is group of materials assembled by a library or a private individual. A library collection consists of both physical items held by the library and digital resources (local and online) selected and orga nized by the library and accessed by library users and staff members" (Johnson 2009). Dengan kata lain, koleksi adalah sekelompok bahan yang dikelola oleh sebuah perpustakaan atau individu. Koleksi sebuah perpustakaan terdiri dari koleksi yang berbentuk fisik yang terdapat di perpustakaan dan sumber-sumber digital (lokal dan online) yang diseleksi dan dikelola oleh perpustakaan dan dapat diakses oleh pengguna perpustakaan dan stafnya.

Besarnya koleksi sebuah perpustakaan ditentukan oleh berbagai faktor seperti jumlah program studi, jumlah mata kuliah (dasar umum, dasar keahlian, bidang studi), tingkat pendidikan (akademi, politeknik, institut, universitas), kegiatan penelitian, banyaknya buku ajar per mata kuliah, dan lain sebgainya. Sejalan dengan itu, koleksi perpustakaan hendaknya jangan terbatas pada pemenuhan kurikulum belaka, tetapi harus memberikan keluasan kepada pemustaka untuk dapat mengembangkan dirinya sesuai dengan bakat dan cita-citanya.

Mengevaluasi koleksi ialah upaya menilai daya guna dan hasil guna koleksi dalam memenuhi kebutuhan civitas akademik serta program perguruan tinggi. Hal ini senada

\footnotetext{
${ }^{2}$ Hasil laporan kegiatan Pusat Perpustakaan IAIN Sykeh Nurjati Cirebon, 2017.

${ }^{3}$ Hasil wawancara dengan Ibu Tuti Alawiyah selaku koordinator bidang pengembangan dan pengadaan bahan pustaka Pusat Perpustakaan IAIN Syekh Nurjati Cirebon, 1 Februari 2018.

4 Hasil wawancara dengan beberapa mahasiswa IAIN Syekh Nurjati Cirebon program studi Sejarah Peradaban Islam, Februari 2018
} 
dengan apa yang dikemukakan oleh Connie van Fleet yang menyatakan bahwa "evaluasi koleksi berfokus pada penentuan kekuatan dan kelemahan dari sebuah bahan koleksi perpustakaan, bagaimana koleksi tersebut dapat mendukung dan memajukan misi dan tujuan perpustakaan yang menaunginya, dan nilai dari koleksi tersebut bagi pengguna perpustakaan" (Wallace dan Fleet 2001).

Berbicara tentang pengertian evaluasi koleksi hakekatnya adalah suatu kegiatan yang bersifat penilaian deskriptif hingga investigasi statistik yang kompleks. Adapun tujuan dari kegiatan evaluasi koleksi ini adalah untuk menyediakan informasi yang relevan, spesifik, dan akurat tentang koleksi tersebut. Ada dua topologi digunakan dalam membahas evaluasi koleksi tersebut. Pertama yaitu evaluasi berdasarkan koleksi (collection-centered) dan evaluasi koleksi berdasarkan penggunaan (use-centered).

Kemudian mengenai evaluasi koleksi berdasarkan metode collection-centered meliputi empat proses dalam melakukan evaluasi, yaitu pencocokan pada daftar tertentu, bibliografi, atau katalog (list checking); penilaian dari pakar (expert opinion); perbandingan data statistik (comparative use statistics); dan perbandingan standar koleksi (collection standards). (Evans dan Saponaro 2005)

1) List Checking

Metode list checking ini sudah tidak asing bagi evaluator. Metode ini dapat digunakan dengan berbagai tujuan, baik dengan satu metode maupun dikombinasi dengan metode lain dan biasanya menghasilkan data numerik. menurut (Evans dan Saponaro 2005) dalam menilai sebuah koleksi, list checking digunakan sebagai bagian dari sebuah proses penilaian. Seringkali, evaluator meminta sampel acak dari pakar subjek di institusi tersebut untuk mengidentifikasi satu atau dua bibliografi atau daftar bahan baku dalam keahlian khusus yang dinilai masuk akal untuk digunakan dalam mengevaluasi koleksi.

2) Expert Opinion

Metode ini bergantung pada keahlian seseorang dalam melakukan penilaian dan penguasaan terhadap subjek yang akan dinilai (Evans dan Saponaro 2005). Dalam metode ini pemeriksaan terhadap koleksi dalam hubungannya dengan kebijakan dan tujuan perpustakaan serta menyiapkan laporan berdasarkan tayangan seberapa baik koleksi tersebut memenuhi tujuan tersebut. Prosesnya bisa memerlukan peninjauan terhadap keseluruhan koleksi menggunakan daftar pergerakan (shelflist). Bisa terbatas hanya pada satu subjek, itu sering terjadi tetapi bisa juga mencakup berbagai subjek tergantung pada penguasaan pakar tersebut.

3) Comparative Use Statistics

Perbandingan diantara institusi dinilai sangat bermanfaat untuk data evaluasi. Namun ada keterbatasan yang disebabkan oleh perbedaan institusional dalam tujuan, programprogram, dan populasi yang dilayani (Evans dan Saponaro 2005). Misalnya, sebuah perguruan tinggi junior yang hanya memiliki program seni liberal memerlukan satu jenis perpustakaan, sedangkan sebuah perguruan tinggi dengan kurikulum seni liberal dan program kejuruan yang kuat membutuhkan koleksi yang jauh lebih besar.

4) Collection Standards

Tersedia berbagai standar yang diterbitkan untuk hampir setiap jenis perpustakaan. Standar itu memuat semua aspek dari perpustakaan. Standarnya sangat bervariasi dari waktu ke waktu dan terkadang bergeser dari pendekatan kuantitatif ke pendekatan kualitatif dan kembali lagi. Pergeseran ini membuat perbandingan pola pikir jangka panjang.

Standar kuantitatif telah terbukti berguna, dalam beberapa kasus, untuk perpustakaan yang tidak mencapai standar atau memiliki nilai "rendah" atau "kelas" rendah. 
Misalnya, edisi awal standar untuk perpustakaan perguruan tinggi memiliki metode penilaian untuk ukuran koleksi berdasarkan persentase yang dimiliki dengan ukuran ideal. Ukuran ideal adalah hasil perhitungan dengan menggunakan begitu banyak buku per kategori seperti jurusan sarjana dan anak di bawah umur, dengan nomor lain untuk setiap program gelar master. Bagi orang lain, standar semacam itu sedikit banyak atau tidak menarik kecuali jika gagal mencapai standar tersebut, institusi tersebut akan menanggung konsekuensi (Evans dan Saponaro 2005).

\section{METODOLOGI PENELITIAN}

Penelitian ini menggunakan pendekatan kualitatif dengan jenis penelitian studi kasus. Adapun penelitian kasus adalah merupakan serangkaian kegiatan ilmiah yang dilakukan secara intensif, terinci dan mendalam tetang suatu peristiwa, program, dan aktivitas baik pada tingkat perorangan, kelompok, lembaga atau organisasi untuk memperoleh pengetahuan mendalam tentang peristiwa tersebut. Peristiwa yang dipilih biasanya bersifat nyata, benar-benar terjadi dan tidak terikat dengan waktu. Berkaitan dengan penelitian kasus Creswell dalam (Sugiyono 2017), menyatakan bahwa :

“...salah satu jenis penelitian kualitatif, dimana peneliti melakukan eksplorasi secara mendalam terhadap program, kejadian, proses, aktivitas, terhadap satu orang atau lebih orang. Suatu kasus terikat oleh waktu dan aktivitas dan peneliti melakukan pengumpulan data secara mendetail dengan menggunakan berbagai prosedur pengumpulan data dan dalam waktu berkesinambungan".

Ada beberapa lasan peneliti menggunakan penelitian kasus. Pertama, permasalahan yang dikaji dalam penelitian ini membutuhkan data yang bersifat kontekstual dan aktual. Kedua, pemilihan ini berdasarkan pada keterkaitan masalah yang dikaji dengan sejumlah data primer dan subjek penelitian yang tidak dapat dipisahkan dari latar belakang alamiahnya. Disamping itu, penelitian ini memungkinkan peneliti untuk senantiasa menyesuaikan diri dengan situasi yang berubah-ubah dalam penelitian. Untuk teknik pengumpulan datanya dilakukan melalui observasi, wawancara mendalam serta melalui studi kepustakaan.

\section{HASIL PENELITIAN}

Sebagaimana yang telah dikemukakan di atas penelitian ini dilakukan di pusat Perpustakaan IAIN Syeh Nurjati Cirebon. Topik yang dikaji dalam penelitian ini adalah tentang evaluasi koleksi metode collection-centered. Ada tiga jenis yang dilakukan untuk melakukan evaluasi berdasarkan metode collection-centered ini yakni pencocokan pada daftar (list checking), pendapat pakar serta berdasarkan standar koleksi. Dari hasil penelitian dapat dikemukakan sebagai berikut :

\section{Pencocokan pada daftar (list checking)}

Dalam melakukan evaluasi koleksi yang mengunakan metode collection-centered, cara pertama yang dilakukan dengan menggunakan pencocokan pada daftar list. Sebagai langkah awal yang dilakukan petugas pustakawan jika menggunakan teknik list cheking adalah dengan menyusun form ceklist yang berisi daftar katalog atau daftar bahan bacaan yang telah disusun dari berbagai penerbit sesuai dengan subjek bidang ilmunya. Selanjutnya form ckecklist ini disebarkan pada pengguna baik mahasiswa, karyawan maupun staf pengajar yang ada di IAIN Syeh Nurjati Cirebon. Namun pada saat ini penyebaran form cekclist lebih diutamakan pada dosen. Adapun yang menjadi alasannya dosen dinilai memiliki wawasan mengenai sistem pembelajaran dan lebih memahami koleksi mana saja yang dibutuhkan dan tepat untuk menunjang proses belajar 
mahasiswanya. Dengan demikian dapat dikatakan bahwa antara pustakawan dan dosen memiliki kerjasama yang baik dalam mencapai tujuan perpustakaan.

Tujuan dari penggunaan form checklist in adalah untuk mengetahui kebutuhan koleksi pemustaka ini disebar ke semua fakultas yang ada di IAIN Syekh Nurjati Cirebon. Masing-masing fakultas kemudian menyebarkan form checklist ini kepada masing-masing program studi yang terdapat didalamnya. Peran para dosen dalam hal ini adalah untuk menceklis koleksi apa saja yang diperlukan sesuai dengan katalog yang disediakan oleh pustakawan. Kurun waktu setelah pustakawan menyebarkan form checklist adalah satu minggu lamanya.

Berdasarkan hasil penelitian menunjukkan bahwa hasil analisis kebutuhan koleksi dengan penyebaran form checklist dari setiap program studi ini menghasilkan jumlah permintaan koleksi yang cukup banyak karena seringkali dosen pun menambahkan daftar pilihan lain diluar apa yang dicantumkan pustakawan. Melihat tingginya permintaan koleksi tersebut, hal yang dilakukan pustakawan adalah melakukan pengecekan terhadap koleksi yang dibutuhkan dengan ketersediaan yang ada di database. Software database yang digunakan adalah SLiMS versi pertama. Apabila koleksi yang dibutuhkan ternyata sudah ada di database, maka koleksi tersebut tidak lagi ada dalam pilihan pengajuan untuk pengadaan. Hal ini sesuai dengan pemaparan Ibu Tuti selaku pustakawan yang menyatakan

“... Perpustakaan menyesuaikan dengan kebutuhan pemakai. Kebutuhan pemakai kan sifatnya untuk tingkat lingkungan civitas akademik kan tarbiyah (Fakultas Imu Tarbiyah dan Keguruan) sama FUAD (Fakultas Ushuluddin Adab dan Dakwah) gitu. Terus kita setelah itu kemudian kita cek. Kita cek terutama di OPAC. Setelah cek di OPAC bahwa apakah buku itu sudah ada atau belum. Kalau memang sudah ada, berapa ketersediaan yang sudah tersedia, yang sudah tersedia berapa di perpustakaan itu. Misalkan yang sudah tersedianya sudah sepuluh, berarti kita tidak menambah lagi kecuali dibawah sepuluh"

Mengenai penggunaan teknik pencocokan pada daftar (list checking) pada prakteknya belum dilakukan secara rutin dan sistematis di Pusat Perpustakaan IAIN Syekh Nurjati Cirebon. Selain itu juga dalam proses pelaksanaannya kadang-kadang ada bagian yang terlewatkan. Namun demikian dengan dilakukannya kegiatan ini bisa mengatasi kesenjangan koleksi yang ada di Pusat Perpustakaan IAIN Syekh Nurjati Cirebon.

\section{Pendapat Pakar (expert opinion)}

Cara kedua yang dilakukan untuk melakukan evaluasi koleksi yang menggunakan menggunakan metode collection-cetered adalah meminta pendapat pada para pakar mengenai jenis koleksi atau subyek apa yang belum ada dan harus dimiliki perpustakaan IAIN Syeh Nurjati Cirebon. Berkaitan dengan proses pengembangan koleksi yang dilakukan IAIN Syeh Nurjati harus mengacu dan sejalan dengan visi dan misi lembaga induknya. Adapun dalam pengadaan koleksi perpustakaan di IAIN Syeh Nurjati berasal dari berbagai bersumber. Sebagai gambaran untuk pengadaan koleksi IAIN Syeh Nurjati Cirebon pada tahun 2018 yang lalu adalah sebagai berikut :

Tabel 1 : Pengadaan Koleksi Perpustakaan IAIN Syekh Nurjati Cirebon

\begin{tabular}{|l|l|l|l|l|}
\hline No & Sumber & Judul & Eksemplar & Bukti Fisik \\
\hline 1 & Anggaran DIPA tahun 2017 & 369 & 1716 & Ada \\
\hline 2 & Hibah dari Bank Indonesia & 257 & 259 & Ada \\
\hline
\end{tabular}




\begin{tabular}{|l|l|l|l|l|}
\hline 3 & Hibah Perpustakaan Nasional RI & 500 & 1000 & Ada \\
\hline 4 & Hibah Alumni Angkatan XV & 236 & 341 & Ada \\
\hline 5 & Hibah Alumni Angkatan XVI & 195 & 635 & Ada \\
\hline 6 & Hibah Mahasiswa, Depag RI, dll & 280 & 317 & Ada \\
\hline 7 & Koleksi Serial & 22 & 33 & Ada \\
\hline \multicolumn{2}{|c|}{ JUMLAH } & 1859 & 4301 & \\
\hline
\end{tabular}

Sumber : IAIN Syeh Nurjati, 2018.

Kemudian berkaitan dengan evaluasi koleksi yang menggunakan pendapat pakar, dalam konteks ini petugas perpustakaan selain menggunakan instrumen lain dalam melakukan evaluasi koleksi juga meminta pendapat dari pakar khususnya para dosen senior mengenai koleksi yang harus ada di perpustakaan sesuai dengan bidang keilmuan atau kepakarannya. Selain dari dosen senior, petugas perpustakaan IAIN Syeh Nurjati juga juga meminta pendapat dan masukan dari setiap program studi berkaitan dengan bukubuku yang harus tersedia di perpustakaan. Upaya meminta pendapat dari para pakar ini sangat penting dilakukan perpustakaan IAIN Sykeh Nurjati Cirebon agar diperoleh informasi mengenai koleksi yang dibutuhkan, sehingga pada gilirannya koleksi yang tersedia adalah koleksi yang sesuai dengan need, demand serta interest para penggunanya dengan tetap menjaga kualitas dari koleksi yang disediakan.

\section{Standar Koleksi (collections standard)}

Dalam melakukan evaluasi yang menggunakan standar koleksi untuk perpustakaan perguruan tinggi ada 6 indikator yakni : (1) Perpustakaan menyediakan akses terhadap koleksi sesuai dengan bidang penelitian, inti kurikulum, atau keunggulan institusi. (2) Perpustakaan menyediakan koleksi dalam berbagai bentuk/format yang dapat diakses secara fisik dan virtual. (3) Perpustakaan membangun dan memastikan akses terhadap koleksi langka/unik, termasuk koleksi digitalnya. (4) Perpustakaan memiliki infrastruktur untuk mengumpulkan, mengorganisasikan, menyediakan akses, mendiseminasikan, dan memelihara koleksi yang diperlukan oleh para pemustaka. (5) Perpustakaan mendidik pemustaka berkaitan dengan model ekonomis dan komunikatif. (6) Perpustakaan memastikan akses jangka panjang terhadap temu balik koleksi.

Berdasarkan penelitian dari indikator tersebut di atas, Perpustakaan IAIN Syekh Nurjati Cirebon baru mencapai tiga indikator yaitu :

1) Perpustakaan IAIN Syeh Nurjati telah menyediakan akses terhadap koleksi sesuai dengan bidang penelitian, inti kurikulum, atau keunggulan institusi.

2) Perpustakaan IAIN Syeh Nurjati telah menyediakan koleksi dalam berbagai bentuk/format yang dapat diakses secara fisik dan virtual. Perpustakaan IAIN Syekh Nurjati Cirebon memiliki koleksi tercetak yang dapat dijumpai disetiap lantai perpustakaan. hingga kini, koleksi tercetak yang dimiliki oleh Pusat Perpustakaan IAIN Syekh Nurjati Cirebon memiliki 65.189 eksemplar koleksi. Untuk koleksi virtual pun dapat diakses di web.syekhnurjati.ac.id. Pustakawan selalu memantau segala bentuk koleksi yang ada di Pusat Perpustakaan IAIN Syekh Nurjati Cirebon demi menjaga kualitas koleksi.

3) Perpustakaan IAIN Syeh Nurjati telah bekerjasama dengan semua staff dalam menyedian infrastruktur dalam rangka mengumpulkan, mengor-ganisasikannya serta menyediakan akses pada berbagai sumber informasi baik fisik maupun secara virtual. 


\section{E. KESIMPULAN}

Berdasarkan hasil penelitian dapat disimpulkan bahwa pelaksanaan evaluasi yang menggunakan teknik pencocokan pada daftar (list checking) di Pusat Perpustakaan IAIN Syekh Nurjati Cirebon belum dilakukan sepenuhnya dan dalam pelaksanaanya kadangkadang ada bagian yang masih terlewatkan. Namun demikian dengan teknik ini pustakawan bisa mengatasi kesenjangan koleksi yang ada di Pusat Perpustakaan IAIN Syekh Nurjati Cirebon. Dalam menyempurnakan koleksi, pustakawan mengadakan seleksi prioritas koleksi yang dilakukan beradasarkan pengecekan pada database (SLiMS) dan juga disesuaikan dengan anggaran yang dikeluarkan oleh pihak universitas untuk perpustakaan.

Kemudian untuk teknik evaluasi yang menggunakan pendapat pakar (expert opinion) berkaitan dengan koleksi di Pusat Perpustakaan IAIN Syekh Nurjati Cirebontelah dilakukan secara terstruktur dan melibatkan beberapa dosen dari perwakilan setiap program studi. Begitu dari untuk evaluasi yang menyangkut standar koleksi menunjukkan bahwa bahwa koleksi di Pusat perpustakaan IAIN Syeh Nurjati Cirebon telah memenuhi tiga indikator standar koleksi secara keseluruhan.

\section{DAFTAR PUSTAKA}

Direktorat Jenderal Pendidikan Tinggi. 1994. Perpustakaan Perguruan Tinggi: Buku Pedoman. Edisi Kedu. Jakarta: Departemen Pendidikan dan Kebudayaan RI.

Evans, G. Edward, dan Margaret Zarnosky Saponaro. 2005. Developing Library and Information Center Collection. Fifth Edit. London: Libraries Unlimited.

Johnson, Peggy. 2009. Fundamentals of Collection Development and Management. Second Edi. Chicago: American Library Association.

Muda, Lisdawati. 2014. "Menciptakan Hubungan Harmonis di Perguruan Tinggi." Manajemen Pendidikan Islam Volume 2,: 58.

Sugiyono. 2017. Metode Penelitian Kualitatif. Bandung: Alfabeta.

Sulistyo-Basuki. 1991. Pengantar Ilmu Perpustakaan. Jakarta: Gramedia Pustaka Utama.

Wallace, Danny P., dan Connie Van Fleet. 2001. Library Evaluation: A Casebook and Can-Do Guide. Englewood: Libraries Unlimited. 